Journal of Economics and Behavioral Studies

Vol. 4, No. 9, pp. 489-496, Sep 2012 (ISSN: 2220-6140)

\title{
Sustainable Development in Developing Countries: Case Studies of Sustainable Consumption and Production in South Africa and India
}

\author{
${ }^{*}$ Ogujiuba Kanayo ${ }^{1}$, Stiegler Nancy ${ }^{1}$, Fadila Jumare ${ }^{2}$ \\ ${ }^{1}$ University of Western Cape; Cape Town-South Africa \\ ${ }^{2}$ National Institute for Legislative Studies Abuja, Nigeria \\ *kannyog@gmail.com
}

\begin{abstract}
The pursuit of development has had a major impact on the environment and on existing social structures. During the 1950s and 1960s, most nations were preoccupied with economic growth and energy consumption, which led to social and environmental issues being overlooked. Thus, traditional societies have been devastated and extreme environmental damage occurring such as pollution and inadequate water supply, transportation and sewer infrastructure problems amongst others. If environmental damage remains unchecked, the achievements of development and even essential ecosystems would be undermined. This paper reviewed the link between growth trends and sustainable development in Sub-Saharan Africa. Thereafter, the impact of environmental degradation was discussed including strategies for sustainable energy production and consumption. These were based on evidence from South Africa and India and provided the benchmark for discussing ways in which energy production and consumption can take place sustainably. The paper notes that in developing and implementing strategies, emerging countries do not necessarily have to be western in their sustainable development policies. Rather, each country has to have sustainable development policies that are peculiar to its own circumstance. The paper recommends community participation and accountability of institutions as necessary for ensuring that social development is integrated into the economic and environmental elements of sustainable development.
\end{abstract}

Key Words: Environment, Economic Growth, Production, Consumption, Sustainable development

\section{Introduction}

Urban air pollution in many cities in developing countries comes from emissions of toxic gases like sulfur oxides (SOJ), nitrogen oxides (NOJ) and carbon monoxide. These and hydrocarbons from industries and vehicles have resulted in deterioration of ambient air quality. This phenomenon generates local pollutants that adversely affect social interests and result in severe health effects (Parikh \& Painuly, 1994). Environmental degradation could also occur from domestic pollution due to consumption of non-commercial fuels such as bio-fuels used by a majority of households in developing countries, especially in rural areas, and urban slums. Today, the international community is increasingly realizing the problems associated with deterioration of the environment (environmental degradation) and resource depletion. However, they maintain that development is unsustainable without considering attendant issues. These issues were being considered as external challenges to be met by fine-tuning the process of global development, measured primarily by rates of economic growth. Having reviewed literature on the link between economic growth and sustainable development, this paper argues that the challenges of environmental degradation should be considered as a direct consequence of the growth process. Therefore, if growth is to be sustainable, what really needs to be addressed is the limit of consumption and a reduction in the increasing wants and needs of society (Gopalan, 2001). More importantly, sustainable development requires a redefinition of growth to develop new technologies while using energy and other resources more efficiently to produce less pollution. The electricity supply sector in developing countries involves the use of a wide choice of technology and fuel sources, which are responsible for high Carbon Dioxide (CO2) emissions. Of great concern is the high level of emissions in countries like South Africa and India, which exhibit rising GDP growth levels and yet produce high quantities of $\mathrm{CO} 2$ emissions. For instance, India is the fourth largest CO2 emitting country in the world, 
following the EU271, and well ahead of Russia, which is the fifth largest (Olivier et al, 2012). According to the same source, India emits more than $5 \%$ of global CO2 emissions, and emissions continue to grow. $\mathrm{CO} 2$ emission has almost tripled between 1990 and 2009 in India and is projected to increase by almost 2.5 times between 2008 and 2035. A large share of this emission is produced by the electricity and heat sector, which represented 54\% of CO2 in 2009, up from 40\% in 1990. Similarly, a report by the (International Energy Agency, 2011) states that South Africa accounted for $40 \%$ of CO2 emissions from fuel combustion in Africa in 2009. The electricity and heat sector produced 62\% of South Africa's CO2 emissions in 2009. Also mentioned by the same source is that, emissions would quadruple between 2003 and 2050 in the absence of radical energy choice changes, dominated by energy-related emissions, notably from the electricity, industrial and transport sectors. Given these challenges, the purpose of this paper is to reveal the environmental implications of these sources and sustainable energy strategies using case studies from South Africa and India. This becomes increasingly important given the external costs incurred in electricity generation including avoidable health costs caused by air pollution, high electricity tariffs and damages from greenhouse gas emissions. As a result, efforts should be made to develop strategies that would consider environmental issues alongside economic and social issues. A focus on sustainable development serves to influence decision making by organizations and can aid in forming principles and values such as planning regulations for green buildings and technologies.

The Concept of Sustainable Development and Interrelationship between Elements: The World Commission on Environmental Development (WCED) defined the concept of sustainable development, 1987 as "Development that meets the needs of the present without compromising the ability of future generations to meet their own needs". Van der Merwe \& Van der Marwe (1999) add that Sustainable development is a program for changing the process of economic development so that it ensures a basic quality of life for all people and at the same time protects the ecosystems and community systems that make life possible and worthwhile. According to Coomer (1979) the sustainable society is one that lives within the self-perpetuating limits of its environment. That society is not a growth society. Rather, it is a society that recognizes the limits of growth and looks for alternative ways of growing. Thus, sustainable development would stipulate that new resources and machines are developed to replace with other environmental resources. One of such efforts is the construction of solar panels to replace oil and coal. Sustainable development is also about being clear and responsible about the levels of pollution and carbon emissions. Carvalho (2001) cites that the idea of limitations imposed by the state is also being emphasized, adding that the critical limits articulation emphasizes the concrete limits to ecological capacity and that ecosystems have finite carrying capacities. Therefore, there is need to preserve these ecosystems and respect their limits or face economic and environmental collapse (Sagoff, 1988; Daly and Cobb, 1989) cited in Carvalho (2001). Sustainable development integrates economic, social with the aforementioned environmental goals. As such, technology has to work within nature's limits (Mebratu, 1998). Dixon \& Pretorius (2001) cite the International Council for Local Environmental Initiatives (ICLEI), which emphasizes environmental, social and economic concerns as three distinct but interrelated components of sustainable development.

Firstly, the economic aspect of sustainable development emphasizes the production of goods and services visà-vis maintenance of external debt as well as avoiding extreme sector imbalances, which damage agriculture or industrial production (Harris, 2000). This aspect of sustainable development has to do with sustaining a stable resource base, avoiding over exploitation of renewable resources and depleting non-renewable resources only to the extent that investment is made in adequate substitutes. Furthermore, the social element of sustainable development requires the achievement of distributional equity, adequate provision of social services such as health, gender equity, social accountability and participation (Harris, 2000). Environmental priorities in developing countries are therefore regulated by the fact that more than 1200 million people lived below poverty level, 2200 million did not have access to sanitation and 1550 million did not have access to safe water, all of which are reflected in high infant mortality (Parikh \&Painuly, 1994). Social sustainability is also derived from access to safe water and sanitation. Access to safe water, especially in rural areas, is yet

1The European Union (EU) is an economic and political union of 27 member states, which are located primarily in Europe. It operates through a system of supranational independent institutions and intergovernmental negotiated decisions by the member states. 
another major problem in developing countries. Lack of safe water is responsible for high infant mortality rates in developing countries, and the lack of ad-equate sanitation facilities is responsible for a number of diseases (Parikh \& Painuly, 1994). In this respect, Carley \& Christie (2000) posit that sustainable development should address social equity and improve the prospects of quality of life for the worst off communities, run-down economies and urban environments. The inter-dependence model recognises that the social and economic systems have never been and can never be independent of the natural system. The model further supports the belief that interactions between and within component, systems will result in feedback throughout the cosmos (Mebratu, 1998).

\section{Literature Review}

The Link between Economic Growth and Sustainable Development: throughout the late 18th and 19th centuries, economists addressed several environmental problems. The classical school believed in some kind of ultimate limit to economic growth, stemming from the finite productive capacity of the soil or what ecologists would today call natures carrying capacity (Friend 1990). For instance, Thomas Malthus and David Ricardo attempted at developing the theory of limits and overpopulation. The Ricardian concept of diminishing returns played a key role in the theory that economic growth had definite limits (Friend, 1990). These may be considered as major precursors for the concept of sustainable development. Many mainstream economists believe that technological progress and market forces can successfully deal with environmental limits to growth. An example of this optimism is reflected in the environmental Kuznet's curve (or inverted ushape curve). This curve suggests that at a certain level of economic development, the total emissions in a given economy start to decrease and the environment improves. However, it is also true that increasing efficiency, economies of scale and therefore diminishing price of goods will cause such a high rise of consumption that no absolute reduction of emissions or resource use will be reached. Moreover, the ecosystem may collapse before the turning point of the Kusnet's curve, which is on an income level that is much too high to be realized on a global level. Nonetheless, income measured in terms of 'economic growth 'usually refers to the positive percentage change of an economy's real GDP from one period to another. GDP is measured by the economy's production of goods and services, reflecting the economy's ability to satisfy people's needs and desires"(Mankiw, 2003) cited in (Sedlacko \& Gjoksi, 2009). Some economists have found empirical evidence to support the view that technology seems to work in favor of environmental quality. They also found that many environmental indicators tend to improve as income increases (Shaflk, 1992). For instance, Goldin \& Winters (1995) claim that sustained economic growth is the key to improved environmental management. However, what these economists failed to address is the tradeoffs in pursuing economic growth and sustainable development. In many countries, more output is accompanied by an increase in unwelcome side effects such as pollution (Baumolet et al, 2007) cited in (Sedlacko \& Gjoksi, 2009). As such, the picture in Sub-Saharan Africa suggests that income increases are associated with higher technological advances and thus higher environmental damage.

To illustrate, Sub-Saharan Africa is said to have enjoyed a remarkable growth takeoff since the mid-1990s. Average growth rates approached those of developing countries elsewhere, and growth in the region was in some ways more persistent than in any previous postwar period (IMF, 2008). The chart below represents a historical data chart for GDP annual percentage growth in Sub Saharan Africa between 2001 and 2012. It is evident that the rates were highest from 2004 to 2008 recording $5.88 \%$ and $6.45 \%$ respectively.

Figure 1: GDP Growth (annual \%) in Sub Saharan Africa

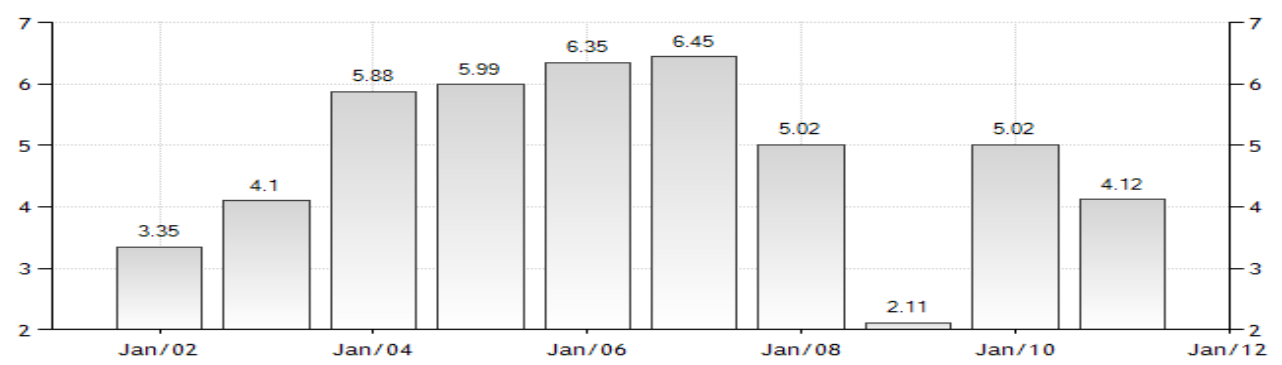

Source: http://www.tradingeconomics.com/sub-saharan-africa/gdp-growth-annual-percent-wb-data.html 
However, improvements in GDP growth in the same period were not matched by any improvements in sustainable development indicators. For example the Carbon Dioxide (CO2) emissions in Sub Saharan Africa was reported at 682342.86 (kt) in 2008, according to the World Bank cited in IMF (2008). The following chart indicates that this figure was a sharp increase from around 630,000 (kt) in 2004.

\section{Figure 2: CO2 Emissions (KT) in Sub Saharan Africa}

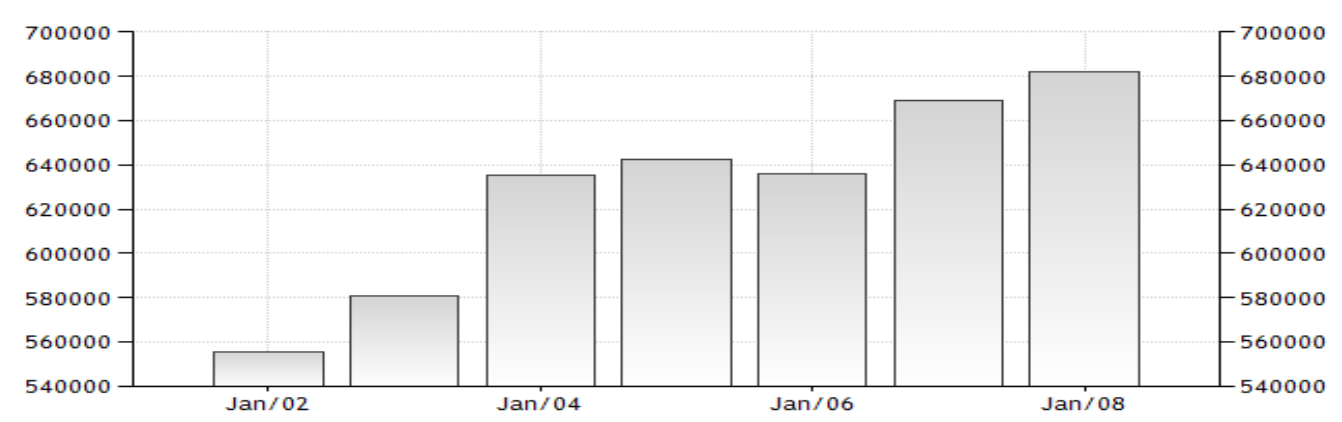

Source: http://www.tradingeconomics.com/sub-saharan-africa/co2-emissions-kt-wb-data.html

In the first meeting of the International Society for Ecological Economics, a society dedicated to the integration of economy and ecology, one of the issues under scrutiny was the deceptive measure of economic performance in Gross National Product (GNP) or GDP (Friend, 1990). These indices were viewed to have serious flaws because they tend to exclude the stock of ecological capital and the social costs of externalities of production and consumption. Given that economic growth cannot occur without deterioration of environment, a significant number of mainstream national and international institutions began to call for development paradigms that de-emphasize economic growth and shift towards sustainable consumption and production patterns. While some have discussed whether economic growth promotes sustainable development, other authors have analyzed commitments of First World countries towards sustainable development in Sub-Saharan Africa. The question mostly asked is how the First World can promote strategies when they are also caught up in highly consumptive lifestyles. Finally, it is also worth noting that poor people are most adversely affected by environmental damage but not much attention is paid to their needs. As such, people oriented strategies were proposed by critics as opposed to large infrastructure projects like huge dams or highways. Further claims are made that through providing aid and investments for sustainable development, more conditions are placed on Third World countries. According to Brown (1996) "recipient countries do not want the industrialized North to attach more restricting strings on either aid or investment in the guise of environmental protection".

\section{Discussion of Case Studies}

It has been recognized, that the problem of achieving sustainable levels of consumption is one not only of prudent/efficient use of available natural resources, but also of operating within the sink capacities of the planetary environment. In the case of food production and consumption for instance, concern is raised regarding the earth's capacity to absorb the degradation of land due to solid waste generated from the extensive package brought in by convenience foods. In addition, high chemical usage must be reduced in order to avoid overexploitation of land, pollution of water and air while still ensuring an acceptable setting for life (Friend, 1990). For over twenty-five years, energy efficiency has made the greatest impact when seen against indicators of sustainable development. Residential energy efficiency is particularly important for social sustainability because it results in significant savings in energy and costs (Winkler, 2006). Sustainable energy is that which provides affordable, accessible and reliable energy sources that meet economic, social and environmental needs while recognizing equitable distribution in meeting those needs (Davidson, 2000a) cited in (Winkler, 2006). Sustainable energy consumption simply entails reduced adverse environmental impacts. 
(i) Energy Savings in Khayelitsha, South Africa: Energy supply in South Africa is dominated by coal, which contributes seventy percent of the country's primary energy (DME, 2005b) cited in (Winkler, 2006). It fuels ninety-three percent of electricity production. In many cases, renewable energy is the lowest cost energy for households and has been expanded in rural areas where poor households are electrified with solar home systems. Brunt \& Knechtel (2005) outline that compared to other major emerging countries, South Africa's emissions intensity is relatively high, in that it emitted $0.96 \mathrm{~kg}$ CO2 per dollar of GDP in 1999 compared to a non-OECD average of 0.66. According to Brunt \& Knechtel (2005) South Africa ranks in the top 20 countries in the world in emissions of greenhouse gases, notwithstanding its relatively small population. Reliance on coal resources for electricity production is the main reason behind this emission profile. Other reasons include the production of synthetic liquid fuels from coal, a high proportion of energy intensive industry and mining, and the inefficient use of energy. These affect ecosystem life-support by significantly reducing options for livelihoods and creating environmental refugees. In other words, there is a reduction in ecological resilience, which constrains options for social and economic development. The social and economic aspects are illustrated in the case study of Kuyasa housing project in the City of Cape Town in partnership with South South North (SSN) a network-based organization operating in Bangladesh, Brazil, Indonesia and South Africa. The project retrofitted low-income housing units in Khayelitsha with solar water heaters, water efficient showers, hot taps and drains, ceilings and ceiling insulation and energy-efficient lighting. In this way, SSN builds capacity among public and private stakeholders to deal effectively with the Clean Development Mechanism (CDM) projects. There are substantial social, economic and environmental benefits to be gained from the project, which reflect a sustainable development pattern. The project has a potential $40 \%$ reduction in electricity usage per household and emission reductions of approximately 2.85 tones of $\mathrm{CO} 2$ per household per year ibid. This shows a high commitment towards achieving environmental sustainability. Other cobenefits of the project activity include a reduction in local air pollution with subsequent decreases in pulmonary pneumonia, carbon monoxide poisoning and other respiratory illnesses. A decrease in accidents and damage to property because of fire is also anticipated. Although the project will receive carbon emission reduction credits over a 21-year period, local communities may not have benefited directly in a meaningful way from the project activities (Brunt \& Knechtel, 2005), meaning that the environmental aspect of sustainability have been favored over social aspects. The community did not benefit in terms of participation. A project like this is expected to ensure that the community is jointly involved in the process and implementation of the project. A top-down approach as such will lead to vulnerability in the long term thereby causing conflict in the community.

(ii) Access to Water and Energy Savings in Vishakhapatnam India: Vishakhapatnam, with a population of 1.2 million, is the second largest city in the Southern Indian state of Andhra Pradesh. Challenges faced in this municipality notably increasing power tariffs and water shortages lead to concern about sustainable development. Only about two-thirds of the urban population has direct access to clean, affordable and reliable drinking water services. At the same time, municipal water utilities in India spend up to $60 \%$ of their budgets on energy used for water pumping (Folke et al, 2002). All these cause loss of resilience and therefore lack of capacity to adapt to environmental shocks. Because of this, there is a loss of opportunity and constrained options to re-organize renew the system and enhance its ability to do different things (Folke et al, 2002). The Vishakhapatnam Municipal Council (VMC) implemented energy-efficiency measures with an investment of only US $\$ 24,500$ from its operations and maintenance funds. The measures included retrofitting pumps and motors, optimizing the use of contracted demand, segregating low tension and high tension and trimming impellers. By implementing these measures, VMC is accruing an annual energy savings of 1.4 million kWh and an annual financial savings of approximately US\$60,400 ibid. This has reduced VMC's annual energy bill for pumping water by about 5.4\% and has reduced $\mathrm{CO} 2$ emissions by about 2,400 metric tons. The simultaneous reductions in municipal wastewater, through more effective supply and distribution, will allow the municipality to deliver water to more homes. The resultant increase in access to water represents social sustainability.

\section{Conclusion and Recommendations}

Notwithstanding their lack of ideas, human capacity and physical infrastructure to integrate sustainability into their development, emerging countries are skeptical about First world countries' commitment towards Sustainable Development. The latter tend to propose as solutions mechanisms that reconcile economic 
growth and environmental protection through technological advances and appropriate development strategies. In addition, they attribute ecological problems to poverty, population growth and underdevelopment without critically examining the roots of these processes. Both these assumptions and proposed solutions reflect a degree of northern bias in that the south becomes a major part of the problem and because such solutions are less likely to work in developing areas (Lohmann, 1990). Unless the social conditions related to equity, justice and participation are addressed first; economic growth and development of new technologies are not likely to lessen the environmental impact of humanity. The participation of international institutions and organizations in the development process is especially important for financing the type of centralized, large-scale, capital and technology intensive strategies of development. They use this platform to impose strategies that strongly affect societies and the natural environment, and that have in general not contributed toward sustainability in the development process (Ascher and Healy, 1990; Rich, 1990, 1994) cited in (Carvalho, 2001). Their western development models pose significant problems and they are said to believe that environmental problems can wait until emerging countries are richer (Harris, 2000). These indicate a lack of regard for the natural environment and social equity (Ascher and Healy, 1990; Rich, 1990, 1994) cited in Carvalho, (2001). However, experts like Mintzer (1992) have suggested that participatory democracy, which allows the voices of the poor to be heard is a prerequisite for achieving sustainable development and this must be un-dominated by vested interests.

Partnership and Participation: Due to the key roles that stakeholders play in the success or failure of many initiatives, partnership and participation are recognised as central to the achievement of sustainable development. In addition, sustainable human communities can be achieved only through a people-centred development. Alternative or people centred development is evident in widespread advocacy of environmental management which is local, participatory or community based. Therefore, in order to build adaptive capacity to build resilience, there is need to involve resource users, decision makers and other interest groups in resource management (Ostrom et al., 1999, Berkes et al., 2002) cited in (Folke et al., 2002).Schumacher (1993) cites the environmental and social advantages of smaller-scale owner operated production. These are people centred approaches, which explicitly place the poor as both victims and agents of environmental degradation at the centre of efforts to understand the environmental aspects of development. According to Chambers (1989) securing livelihoods for the poorest is the key to sustainable development. Howbeit, local people organize best around the problems they consider most important. Thus, local participation ensures voluntary commitment of resources and local control over the quality and distribution of benefits.

Accountability: The principle of accountability ensures that all stakeholders including authorities are accountable for their actions. This can be implemented inter alia by introducing financial liability for actions that inhibit, prevent, delay or retard sustainable development (Hounsome\& Ashton, 2001). Accountability also prevents corruption. Roy (1998) maintains that Corruption increases the cost of and reduces the benefits from development programs to the society. As a result, the gap between the potential and realized achievements continues to widen thereby further undermining the countries' chances of achieving sustainable development. Successful ecosystem management requires monitoring, ecological understanding and institutional capacity to respond to environmental feedback. In addition, political will is essential to make such management possible (Folke et al, 2002). Folke et al (2002) note that in order to build adaptive capacity for sustainable development, the ecological system should be constantly monitored and management decisions should be regularly revisited and changed as knowledge advances. The need for policy frameworks with clear directions for action towards building adaptive capacity would become the threshold for sustainable development. An important question is how governments and business industries may be persuaded to embark on strategic changes to a sustainable future. Since energy intensive activities are the cause of most pollution in developing countries, future research may address the effectiveness of sustainable energy efficiency strategies put forward by International Institutions. This will enable researchers to identify best practices bearing in mind each country's circumstance. 


\section{References}

Brunt, C. \& Knechtel, A. (2005).Delivering sustainable development benefits through the Clean Development Mechanism. Alberta: The Pembina institute

Brown, J. (2006). What Is Sustainable Development? in "Global Vistas" the newsletter of the International Studies Education Project of San Diego (ISTEP),Center for Latin American Studies, San Diego State University. Online [Available]: http://www.globallearningnj.org/iste.htm (Accessed September 3rd 2012).

Carley, M. \& Christie, I. (2000).Managing sustainable development .London: Earth scan publications limited.

Carvalho, G. 0. (2001). Sustainable Development: Is it Achievable within the existing international political economy context? Sustainable Development, 9(2), 61-73.

Chambers, R. (1986). Sustainable Livelihoods: an opportunity for the World Commission on Environmental and Development. Brighton, UK: Institute of Development Studies, University of Sussex.

Coomer, J. (1979). The Nature of the Quest for a Sustainable Society. In: J. Coomer (ed.), Quest for a Sustainable Society. Oxford: Pergamon Press.

Dixon, Y. \& Pretorious, J.G. (2001).Sustainable development. A South African perspective. Online [Available]: http://www.helsinki.fi/imua2001/Pretorius.pdf. [Accessed 15th March, 2011]

Folke, C. (2002). Resilience and sustainable development: Building adaptive capacity in a world of transformation. AMBIO: A journal of the human environment, 31(5), 437-440.

Friend, A.M. (1990). Economics, Ecology and Sustainable Development: Are they compatible? Ottawa: Institute for Research on Environment and Economy, University of Ottawa.

Goldin, I. \& Winters L.A. (1995).The Economics of Sustainable Development. Cambridge: University of Cambridge Press.

Gopalan, R. (2001). Sustainable Food Production and Consumption: Agenda for Action. Economic and Political Weekly, 36(14/15), 1207-1225.

Harris, J. M., Wise, T. A., Gallagher, K. P. \& Goodwin, N. E. (2001).A survey of sustainable development. Washington, DC: Island Press.

Hounsome, R. \& Ashton, P. (2006).Sustainable Development for the Mining \& Minerals Sector in Southern Africa: Draft position paper for the mining, minerals and sustainable development Online [Available]: projecthttp://www.mining.wits.ac.za/Peterob.doc [Accessed 15 June 2012].

International Energy Agency Statistics. (2011). IEA Statistics: CO2 emissions from fuel combustion Highlights, International Energy Agency. Online [Available]: http://www.iea.org/co2highlights/co2highlights.pdf (Accessed September 3, 2012)

International Monetary Fund. (2008). Regional economic outlook: Sub-Saharan Africa. Washington DC: World economic and financial surveys Online [Available] http://www.imf.org/external/pubs/ft/reo/2012/afr/eng/sreo0412.pdf (Accessed September 3 2012).

Lohmann, L. (1990). Whose common future? The Ecologist, 20(3), 82-84.

Mebratu, D. (1998) Sustainability and sustainable development: Historical and conceptual overview. Environ Impact Asses and Review, 18, 493-520.

Mintzer, I.M. (1992).Confronting Climate Change: Risks, Implications and Responses. Cambridge: Cambridge University Press.

Olivier, G. J., Janssens-Maenhout, G. \& Peters J. A. H. (2012). Trends in global co2 emissions 2012 report. Netherlands: Environmental Assessment Agency \& European Commission Joint Research Centre

Parikh, J. K. \& Painuly, J. P. (1994). Population, consumption patterns and climate change: A socioeconomic perspective from the South. Ambio, 23, 434-437.

Roy, K.C. (1998). Good governance and sustainable institutions: The impact of institutions. International journal of social economics, 3, 1-26.

Shaflk, N. \& Bandyopadhay, S. (1992).Economic growth and environmental quality, time series and cross country evidence background paper for the World Development Report, World Bank, Washington, DC.

Sedlacko, M. \& Gjoksi, N. (2009). Sustainable development and economic growth: Overview and reflections on initiatives in Europe and beyond. Vienna: European Sustainable Development Network.

Schumacher, E. F. (1973). Small is Beautiful: Economics as if People Mattered. New York: Harper and Row. 
Vander-Merwe, I. \& Van-der-Merwe, J. (1999).Sustainable development at the local level: An introduction to local agenda 21. Pretoria: Department of environmental affairs and tourism.

Winkler, H. (2006).Energy policies for sustainable development in South Africa: Options for the future. Energy Research Centre, Cape Town, Online [Available]: www.erc.uct.ac.za/Research/publications/06Winkler_Energy\%20policies\%20for\%20SD.pdf [accessed 15 $5^{\text {th }}$ May 2012].

Winkler, H. \& Van-Es, D. (2007). Energy efficiency and the CDM in South Africa: Constraints and opportunities. Journal of Energy in Southern Africa, 18(1), 29- 38. 